\title{
Iron Ion Sensor Based on Functionalized ZnO Nanorods
}

\author{
Kimleang Khun, Zafar Hussain Ibupoto, Syed Usman Ali, Chan Ouern Chey, \\ Omer Nur and Magnus Willander
}

\section{Linköping University Post Print}

N.B.: When citing this work, cite the original article.

This is the authors' version of the original publication:

Kimleang Khun, Zafar Hussain Ibupoto, Syed Usman Ali, Chan Ouern Chey, Omer Nur and Magnus Willander, Iron Ion Sensor Based on Functionalized ZnO Nanorods, 2012, Electroanalysis, (24), 3, 521-528.

http://dx.doi.org/10.1002/elan.201100494

Copyright: Wiley-VCH Verlag Berlin http://www.wiley-vch.de/publish/en/

Postprint available at: Linköping University Electronic Press

http://urn.kb.se/resolve?urn=urn:nbn:se:liu:diva-76018 


\section{Iron ion sensor based on functionalised $\mathrm{ZnO}$ nanorods}

Kimleang Khun ${ }^{1}$, Zafar Hussain Ibupoto, Syed Muhammad Usman Ali, Chan Oeurn Chey, Omer Nur, Magnus Willander

Physical Electronics and Nanotechnology Division, Department of Science and Technology, Campus Norrköping, Linköping University, SE-60174 Norrköping, Sweden

\section{Abstract}

In this work, we are presenting an iron ion $\left(\mathrm{Fe}^{3+}\right)$ potentiometric sensor based on functionalized $\mathrm{ZnO}$ nanorods with selective ionophore (18 crown 6). Zinc oxide nanorods with a diameter of about 100 to $150 \mathrm{~nm}$ and $1 \mu \mathrm{m}$ in length were grown on gold coated glass. The selective $\mathrm{Fe}^{3+}$ ionophore sensor with highly aligned $\mathrm{ZnO}$ nanorods has given high sensitivity, acceptable selectivity, reproducibility and stable signal response for detecting $\mathrm{Fe}^{3+}$. The potentiometric response of the $\mathrm{Fe}^{3+}$ sensor with functionalized $\mathrm{ZnO}$ nanorods versus a $\mathrm{Ag} / \mathrm{AgCl}$ reference electrode was observed to be linear over a logarithmic concentration range from $10^{-5} \mathrm{M}$ to $10^{-2} \mathrm{M}$. The detection limit of the proposed sensor was about $5 \mu \mathrm{M}$, which is lower than the normal blood concentration of $\mathrm{Fe}^{3+}$ which is about $10 \mu \mathrm{M}$ and can be up to $30 \mu \mathrm{M}$. The sensitivity of proposed $\mathrm{Fe}^{3+}$ sensor was found to be $70.2 \pm 2.81$ $\mathrm{mV} /$ decade with regression coefficient $\mathrm{R}^{2}=0.99$ and a response time less than 5 seconds. The functionalized $\mathrm{ZnO}$ nanorods with selective iron ionophore has a life time greater than one month and has shown insignificant interference with other ions usually present in the human blood serum. The proposed sensor was used as an indicator electrode for potentiometric titration.

Key words: Immobilization, Ionophore (18 crown 6), Potentiometric chemical sensors, and $\mathrm{ZnO}$ nanorods.

\footnotetext{
${ }^{1}$ Corresponding author at: Physical Electronics Group, Physical Electronics and Nanotechnology Division, Department of Science and Technology, Campus Norrköping, Linköping University, SE-60174 Norrköping, Sweden. Tel.: +46 11363119.

E-mail address: kimleang.khun@liu.se (Khun Kimleang).
} 


\section{INTRODUCTION}

In recent past years, one of the most important semiconductors in research is zinc oxide $(\mathrm{ZnO})$. This is due to its many one-dimensional nanostructures such as nanorods, nanotubes, nanowires and nanobelts beside the many interesting properties. These nanostructures have been highly important for nano-photonic applications such as light emitting diodes, optical waveguides and nanolaser [1-7]; and to sensor applications like gas sensors $[8,9]$ and chemical and biosensors $[10,11]$. However, the high surface to volume ratio of the former is the difference between an epilayer and a nanostructure of the same material. This high surface to volume ratio is important for sensor applications [8-11].

In addition, understanding the surface chemical inceptions in $\mathrm{ZnO}$ nanostructures are very important for sensor devices, due to the fact that sensor devices depend on the ownerships of surfaces. As an example, the hydroxyl $(\mathrm{OH})$ radical on the tetrahedral geometry of $\mathrm{ZnO}$ restricts the surface assimilation of ethanol $[12,13]$. The high proportion of $\mathrm{OH}$ radical can decreases the surface activity of the $\mathrm{ZnO}$ sensor, stops the reaction sites for ethanol molecules and gives less sensing signal.

Iron is a vital element in the human body and is taking effective role in oxygen transport, storage and also in electron transport $[14,15]$. The enzymes which are taking part in the synthesis of amino acids, hormones and neurotransmitters need $\mathrm{Fe}^{3+}$. There is around $10-15 \mathrm{mg}$ of iron to be exhibited in the food daily intake, and studies report that the normal subjects assimilate around $10 \%$ of the amount of iron from the food [16]. Due to the deficiency of iron, the amount of red blood cells in the body reduces and can become a cause of anaemia. In addition, the surplus amount of iron is stored in the heart, liver and other organs $[17,18]$ and this extra iron cannot be spontaneously released from the body, but it is stored as mentioned above and can put other organs at risk of impairment [19]. Moreover, excess or less iron compounds in the human body are also cancer causing factors [20]. It is therefore very important for clinical, environmental and industrial purposes to efficiently detect $\mathrm{Fe}^{3+}$.

There are many methods for the detection of iron ions such as atomic absorption spectroscopy (AAS) [21], inductively coupled plasma (ICP) [22], etc. But these methods have many limitations such as high cost and instability if a large number of samples analysis is needed [21, 22]. Moreover, the potentiometric based sensing method is simple, inexpensive, rapid and more reliable for the analysing for ions detection. In the literature, it is also reported that ion selective electrodes (ISEs) was used for the determination of cations 
[23-28] as well as anions [29-31] and is also used for pharmaceutical compounds [32-36], with some research also reported on $\mathrm{Fe}^{3+}$ detection [37-43]. It is clear that it is necessary to improve the sensitivity of $\mathrm{Fe}^{3+}$ sensors and develop selective electrodes having relatively quick response for the determination of the $\mathrm{Fe}^{3+}$ concentration; especially when small volumes of the sample is available.

In the present study, a $\mathrm{Fe}^{+3}$ sensor based on functionalised $\mathrm{ZnO}$ nanorods with 18 crown-6 is developed and the sensor was highly sensitive and can be used for small volumes of analyte solutions.

\section{Experiment}

\subsection{Materials}

Chemicals 18-crown-6 (18CE6) [Fluka] was used as the ionophore for iron ion selectivity, while Dioctyl phenylphosphonate (DOPP) [Aldrich] was used as plasticizer. Polyvinylchloride (PVC) [Fluka] was used as the membrane matrix, ferric chloride hexahydrate $\mathrm{FeCl}_{3} \cdot 6 \mathrm{H}_{2} \mathrm{O}$ (sigma Aldrich) and trahydrofuran (THF) [Fluka] were used as solvents. All chemicals were of analytical grade.

\subsection{The Fabrication and Preparation of the ZnO Nanorods and their Morphological Characterisation}

The growth of the $\mathrm{ZnO}$ nanorods and fabrication of the substrate is given below. A glass substrate $\left(70 \times 30 \mathrm{~mm}^{2}\right)$ was first cleaned with deionized water and it was then dried by air. After that the glass substrate was placed on a flat support inside a vacuum chamber (Evaporator Satis CR725). We evaporated $30 \mathrm{~nm}$ thickness of titanium followed by $120 \mathrm{~nm}$ of gold. Before growth, the gold coated glass was first washed with isopropanol, followed by deionized water and was again dried in air. $\mathrm{ZnO}$ nanorods were grown onto the gold coated glass by using the aqueous chemical growth method [44]. First a uniform layer of a seed solution (zinc acetate dehydrate) was spin coated on the gold coated glass at $3000 \mathrm{rpm}$, and then the substrate was annealed at $115^{\circ} \mathrm{C}$ in an oven for 20 minutes. Then the substrates were suspended in a Teflon holder and put into an aqueous solution of $0.075 \mathrm{M}$ zinc nitrate hexahydrate $\left[\mathrm{Zn}\left(\mathrm{NO}_{3}\right)_{2} \cdot 6 \mathrm{H}_{2} \mathrm{O}\right]$ and $0.075 \mathrm{M}$ hexamethylenetetramine $\left[\mathrm{C}_{6} \mathrm{H}_{12} \mathrm{~N}_{4}\right]$. The beaker was kept into the oven for 5 to 7 hours at $95{ }^{\circ} \mathrm{C}$. After that the $\mathrm{ZnO}$ grown substrates were taken out from the oven and washed with deionized water, dried by air and the nanostructures were characterised by field emission scanning electron microscopy (FESEM). The FESEM results show that the grown $\mathrm{ZnO}$ nanorods were dense with good alignment and controlled 
length as shown in figure 1a. The morphological characteristics of the grown nanorods can be controlled by changing the growth parameters like the concentration of the seed solution, growth temperature and the $\mathrm{pH}$ of the aqueous solution [45].

\subsection{Functionalization of the ZnO Nanorods with Selective Iron}

\section{Ionophore}

The ionophore membrane was prepared by the following composition, $1 \%$ ionophore (18 crown 6), 33\% PVC and 66\% plasticizer (DOPP) [46]. An amount of 400mg of these components were dissolved into $5 \mathrm{ml}$ of trahydrofuran (THF) in $25 \mathrm{ml}$ glass bottle. Then the $\mathrm{ZnO}$ nanorods grown on gold coated glass substrate were vertically dipped into the ionophore solution for 5 minutes and left for drying for 1-2 hours at room temperature. SEM image of functionalised $\mathrm{ZnO}$ nanorods is shown in figure $1 \mathrm{~b}$. All the functionalised $\mathrm{ZnO}$ nanorods sensors were kept at $4{ }^{\circ} \mathrm{C}$ when not in use. The proposed $\mathrm{Fe}^{3+}$ sensors were used as working electrode for the potentiometric measurements in an electrolytic solution of ferric chloride hexahydrate with a concentration range from $10^{-6} \mathrm{M}$ to $10^{-2} \mathrm{M}$ [46]. $\mathrm{A} \mathrm{Ag} / \mathrm{AgCl}$ was acting as a reference electrode. The output voltage of this experiment for each concentration of ferric chloride hexahydrate solution is recorded by using $\mathrm{pH}$ meter (model 826 Metrohm). The time response of the developed sensor electrode was measured using Keithley 2400.

\section{Result and Discussion}

\subsection{Response Time of the Functionalised ZnO Nanorods Iron Selective}

\section{Electrode}

The construction of the cell potential of the developed $\mathrm{Fe}^{3+}$ sensor presented here can be shown by the diagram bellow:

\section{$\mathrm{Au}|\mathrm{ZnO}|$ membrane $\mid$ testing solution $\| \mathrm{Cl}^{-}|\mathrm{AgCl}| \mathrm{Ag}$}

The cell voltage is a function of the concentration of the testing electrolyte solution. This means that the voltage changes because of the change in concentration of iron ion in the testing solution. During the measurement, we tested the selective $\mathrm{Fe}^{+3}$ sensor into $10^{-6} \mathrm{M}$ iron electrolytic solution and we observed that the output response of the $\mathrm{Fe}^{+3}$ sensor was not stable. Then this $\mathrm{Fe}^{+3}$ sensor was tested in $5 \times 10^{-6} \mathrm{M}$ and the proposed $\mathrm{Fe}^{+3}$ sensor responded with stable output response. Further we checked the response of the functionalised $\mathrm{ZnO} \mathrm{Fe}$ electrode into $10^{-5} \mathrm{M}$ to $10^{-2} \mathrm{M}$, and observed that the $\mathrm{Fe}^{+3}$ sensor showed very stable output voltage for this concentration range. This is shown in the calibration curve of the logarithm concentration of $\mathrm{Fe}^{3+}$ versus the output voltage response. We added $2 \mathrm{ml}$ of $10^{-1} \mathrm{M}$ of $\mathrm{KNO}_{3}$ solution in each testing ferric chloride hexahydrate solution in order to adjust the ionic 
concentration inside the solution. In all our measurements the proposed $\mathrm{Fe}^{3+}$ sensor obeyed the Nernst's equation. Which states:

$$
E=E_{0}-0.05916 \frac{V}{N} \log _{10} \frac{[\text { Reduceed }]}{[\text { Oxidized }]}
$$

Where $E$ is the upper voltage and $E_{0}$ is the intercept of the curve with the y-axis of the calibration curve. The response of the iron ion sensor was about $63 \mathrm{mV}$ for $10^{-4} \mathrm{M}$ solution of ferric chloride hexahydrate. We investigated the output voltage and found that the response did not change with the change of the volume of the testing solution. We repeated the measurement in volume ranging from $5 \mathrm{ml}$ to $20 \mathrm{ml}$ with the same selective electrode into the $10^{-4} \mathrm{M}$ testing solution; the constant output voltage was around 63 to $64 \mathrm{mV}$ for each volume of the testing solution. The sensing mechanism of the electrochemical iron ion sensor followed the equation below:

$$
\begin{gathered}
{\left[\mathrm{Fe}^{3+}\left(\mathrm{H}_{2} \mathrm{O}\right)_{6}\right]^{3+}+18 \mathrm{CE} 6=\left(\mathrm{Fe}^{3+}-18 \mathrm{CE} 6\right)^{3+}+6 \mathrm{H}_{2} \mathrm{O}} \\
\left(\mathrm{Fe}^{3+} 18 \mathrm{CE} 6\right)^{3+}+\mathrm{ZnO}=\mathrm{ZnO}\left(\mathrm{Fe}^{3+}-18 \mathrm{CE} 6\right)^{3+}
\end{gathered}
$$

The proposed iron ion sensor has shown good linearity for a wide concentration range from $10^{-5} \mathrm{M}$ to $10^{-2} \mathrm{M}$ of iron ions. We found that the sensitivity of the sensor is about $70.2 \pm$ $2.81 \mathrm{mV} /$ decade with a regression coefficient $\mathrm{R}^{2}=0.99$. The response time of the electrode was less than 5 seconds as shown in figure $2 \mathrm{a}$ and $2 \mathrm{~b}$, respectively. These two parameters, the response time and the sensitivity fully describe the high efficiency of this proposed iron ion selective electrode.

\subsection{Reproducibility, Linearity and Stability of the Sensor}

We tested the linearity, stability and reproducibility of proposed sensor by using 4 iron ion selective sensor electrodes prepared separately using the same procedure, the relative standard deviation of the functionalized $\mathrm{ZnO}$ nanorods iron sensor in the known concentration of ferric chloride hexahydrate solution was varying with less than $3 \%$. This indicated a good reproducibility. The reproducibility from one iron sensor to another iron sensor in a $10^{-4} \mathrm{M}$ ferric chloride hexahydrate solution is shown in figure $3 \mathrm{a}$. We also checked (three times) the reproducibility of the same iron sensor in ferric chloride hexahydrate solution and the observed results with long stability and excellent linearity as shown in figure $3 \mathrm{~b}$. The proposed sensor was used from time to time and kept at $4{ }^{\circ} \mathrm{C}$ for more than four weeks. The sensor maintained its actual working activity up to $90 \%$ and almost gave the same response towards the iron ion. We investigated the morphology of the used $\mathrm{ZnO}$ membrane 
iron sensor using SEM and the result is given in figure 1c. From the SEM images it was observed that the $\mathrm{ZnO}$ nanorods were slightly affected during the measurements. This is due to the small change in $\mathrm{pH}$ of the testing solution. The solubility of $\mathrm{ZnO}$ nanorods can vitiate the performances of the working electrode.

\subsection{The Effect of Temperature and Interference on the Response of the} Functionalized ZnO Nanorods Selective Iron Ion Sensor

The temperature effect on the functionalized $\mathrm{ZnO}$ nanorods selective iron ion sensor was investigated between temperatures of $21{ }^{0} \mathrm{C}$ to $80{ }^{0} \mathrm{C}$ using $10^{-4} \mathrm{M}$ of ferric chloride hexahydrate solution as shown in figure $4 \mathrm{a}$. We observed that the output voltage was increasing gradually from $21{ }^{\circ} \mathrm{C}$ to $50{ }^{\circ} \mathrm{C}$. Above $50{ }^{\circ} \mathrm{C}$ the output tends to decrease and at 80 ${ }^{\circ} \mathrm{C}$ there was a drastic reduction in voltage due to the decrease in the strength of bonds between the ionophore and the $\mathrm{ZnO}$ nanorods and as the temperature increases, the ionic mobility of the iron ions increases which in result make more resistance to the movement of the iron ions towards the respective functionalized $\mathrm{ZnO}$ nanorods selective electrode. It was reported that using the present ionophore for constructing $\mathrm{Fe}^{3+}$ sensor would give a maximum response in a $\mathrm{pH}$ between 1 to 3 [46], but above this $\mathrm{pH}$ the signal become unstable due to the possible interference of hydrogen ions $\left[\mathrm{H}^{+}\right]$. The interference is one of the most important measuring parameter for ion selective electrode systems. For these measurements we prepared a testing solution with concentration ranging from $10^{-6}$ to $10^{-2} \mathrm{M}$ of each interfering substance, and then performed the potentiometric measurements. The measured output voltage of $\mathrm{Fe}^{3+}$ sensor in presence of the interfering ions with difference concentrations was plotted against the logarithm of concentration using the mixed solution method as shown figure $4 \mathrm{~b}$ and as well as we calculated the selectivity coefficient $\left(\boldsymbol{K}_{\boldsymbol{F e} \boldsymbol{e}^{\mathbf{3}}, \boldsymbol{i o n}}^{\boldsymbol{p o t}}\right)$ for each interfering ion using the separation method [47] as given in table 1. The possible interfering substances that we chose for our experiments were $\mathrm{Na}^{+}, \mathrm{Zn}^{2+}, \mathrm{Cu}^{2+}, \mathrm{K}^{+}, \mathrm{Li}^{+}, \mathrm{Mg}^{2+}$ and $\mathrm{Ca}^{2+}$. Figure $4 \mathrm{~b}$ and Table 1 show that no significant interference was observed.

\subsection{Potentiometric Titration}

The analytical application of $\mathrm{Fe}^{3+}$ sensor based on the functional of $\mathrm{ZnO}$ nanorods was tested by the potentiometric titration of $\mathrm{Fe}^{3+}$ with EDTA solution. A $20 \mathrm{ml}\left(10^{-4} \mathrm{M}\right)$ of testing solution was titrated with $10^{-4} \mathrm{M}$ EDTA solution. With the addition of EDTA solution into the testing solution, the $\mathrm{Fe}^{3+}$ concentration and the output voltage were decreased because of the formation of Fe-EDTA complex as shown in figure 5. In figure 5, which 
exhibits that the end point represent the stochiometric formulation of Fe-EDTA complex and it also suggests that the almost all of the iron ions are used up in the formation of Fe-EDTA complex and so after the equivalent point, the potential response was found to almost be constant. It is therefore suggested that the proposed sensor based on functionalized $\mathrm{ZnO}$ nanorods can successfully be used as an indicator electrode for the determination of $\mathrm{Fe}^{3+}$ by potentiometric titration.

Table 1: The logarithm of selective coefficients for $\mathrm{Fe}^{3+}$ sensor with different interfering ions in $10^{-4} \mathrm{M}$

\begin{tabular}{lr}
\hline Interference ions & $\log \mathbf{K F e}_{F+, \text { ion }}^{\text {pot }}$ \\
\hline $\mathbf{K}^{1+}$ & 0.142 \\
$\mathbf{M g}^{2+}$ & 0.114 \\
$\mathbf{L i}^{1+}$ & 0.027 \\
$\mathbf{Z n}^{2+}$ & 0.222 \\
$\mathbf{N a}^{1+}$ & 0.563 \\
$\mathbf{C a}^{2+}$ & 0.135 \\
$\mathbf{C u}^{2+}$ & 0.560 \\
\hline
\end{tabular}


Table 2: Comparison of the result of the proposed $\mathrm{Fe}^{3+}$ sensor based on $\mathrm{ZnO}$ nanorods with previous published work

\begin{tabular}{ccccccc}
\hline No. & $\begin{array}{c}\text { Slope } \\
(\mathbf{m} \text { /decade })\end{array}$ & $\begin{array}{c}\text { Times respond } \\
(\mathbf{s})\end{array}$ & $\begin{array}{c}\text { Detection } \\
\text { Limit }(\mathbf{M})\end{array}$ & $\begin{array}{c}\text { Linear range } \\
(\mathbf{M})\end{array}$ & Life times & Reference \\
\hline $\mathbf{1}$ & $19.4 \pm 0.5$ & $\approx 15$ & $6.8 \times 10^{-7}$ & $1.0 \times 10^{-6}-1.0 \times 10^{-1}$ & 9 weeks & {$[36]$} \\
$\mathbf{2}$ & 28.5 & $\approx 15$ & - & $3.5 \times 10^{-6}-4.0 \times 10^{-2}$ & 2 months & {$[37]$} \\
$\mathbf{3}$ & 20.0 & 15 & $5.0 \times 10^{-6}$ & $6.3 \times 10^{-6}-1.0 \times 10^{-1}$ & 2 months & {$[38]$} \\
$\mathbf{4}$ & 60.0 & $25-30$ & - & $1.0 \times 10^{-6}-1.0 \times 10^{-2}$ & 3 months & {$[39]$} \\
$\mathbf{5}$ & $30.5-32$ & $8-15$ & $1.0 \times 10^{-6}-4 \times 10^{-8}$ & $5.0 \times 10^{-7}-1.0 \times 10^{-2}$ & $\approx 3$ months & {$[40]$} \\
$\mathbf{6}$ & $19.4 \pm 0.5$ & - & $3.6 \times 10^{-7}$ & $1.0 \times 10^{-6}-1.0 \times 10^{-2}$ & 2 months & {$[41]$} \\
$\mathbf{7}$ & 57.0 & 30 & $1.0 \times 10^{-6}$ & $1.0 \times 10^{-4}-1.0 \times 10^{-1}$ & 2 months & {$[42]$} \\
$\mathbf{8}$ & 20 & 20 & $1.3 \times 10^{-6}$ & $1.0 \times 10^{-5}-1.0 \times 10^{-1}$ & 2 months & {$[45]$} \\
$\mathbf{9}$ & $70.2 \pm 2.81$ & $\approx 5$ & $5.0 \times 10^{-6}$ & $1.0 \times 10^{-5}-1.0 \times 10^{-2}$ & 4 weeks & this work \\
\hline
\end{tabular}




\section{Conclusions}

In this work, we developed a simple, highly sensitive and selective iron ion chemical sensor based on $\mathrm{ZnO}$ nanorods coated by a selective ionophore (18 crown 6). The response

of the sensor increases with increasing the concentrations of the iron ion from $10^{-5} \mathrm{M}$ to $10^{-2} \mathrm{M}$ with a slope $70.2 \pm 2.81 \mathrm{mV} /$ decade. The potential of the presented proposed iron ion sensor is due to its large slope, with a regression coefficient $R^{2}=0.99$ and the relatively small response time obtained (less than 5 seconds). These characteristics of the presented sensor reflect its high sensitivity. Since this sensor is inexpensive, highly selective, and easy to handle for new users and it can be applied for monitoring of iron concentration in human blood serum and in detection of iron from lubrication oils as well as for the environmental analysis it can be of potential in for applications. This iron sensor based on functionalized $\mathrm{ZnO}$ nanorods can also be applied as an indicator electrode for the potentiometric titration.

\section{Acknowledgements}

We are thankful to International Science Programme (ISP), Uppsala University, Sweden and the Royal University of Phnom Penh (RUPP), Cambodia, who financially supported to this research work. 


\section{Reference}

[1] M. H. Huang, S. Mao, H. Feick, H. Yan, Y. Wu, H. Kind, E. Weber, R. Russo, P. Yang, Science 2001, 292, 1897.

[2] J. C. Johnson, H.-J. Choi, K. P. Knutsen, R. D. Schaller, P. Yang, R. J. Saykally, Nat. Mater. 2002, 1, 106.

[3] X. Duan, Y. Huang, R. Agarwal, C. M. Lieber, Nature (London) 2003, 421, 241.

[4] M. Law, D. J. Sirbuly, J. C. Johnson, J. Goldberger, R. J. Saykally, P. Yang, Science 2004, 305, 1269.

[5] C. J. Barrelet, A. B. Greytak, C. M. Lieber, Nano Lett. 2004, 4, 1981.

[6] A. B. Greytak, C. J. Barrelet, Y. Li, C. M. Lieber, Appl. Phys. Lett. 2005, 87, 151103.

[7] M. Willander, L. L. Yang, A. Wadeasa, S. U. Ali, M. H. Asif, Q. X. Zhao, O. Nur, J. Mater. Chem. 2009, 19, 1006.

[8] H. Zhang, J. B. Wu, C. X. Zhai, N. Du, X. Y. Ma, D. R. Yang, Nanotechnology 2007, 18,455604 .

[9] L. Liao, H. B. Lu, J. C. Li, C. Liu, D. J. Fu, Y. L. Liu, Appl. Phys. Lett. 2007, 91, 173110 .

[10] A. Wei, X. W. Sun, J. X. Wang, Y. Lei, X. P. Cai, C. M. Li, Z. L. Dong, W. Huang, Appl. Phys. Lett. 2006, 89, 123902.

[11] A. Umar, M. M. Rahman, S. H. Kim, Y. B. Hahn, J. Nanosci. Nanotechnol. 2008, 8, 3216.

[12] Z. K. Bai, C. S. Xie, M. L. Hu, S. P. Zhang, D. W. Zeng, Mater. Sci. Eng. B 2008, 149 12.

[13] W. Schmid, N. Barsan, U. Weimar, Sens. Act. B 2003, 89232.

[14] R.A. Goyer, Toxic effects of metals, in: C.D. Klaassen (Eds.), Casarett \& Doull's Toxicology: the basic science of poisons, 5th Ed. New York City, NY, McGraw-Hill, 1996, pp. 715-716.

[15] W.F. Greentree, J.O. Hall, Iron toxicosis, in: J.D. Bonagura, (Eds.), Kirk's current therapy XII small animal practice. Philadelphia, Pa, WB Saunders Co, 1995, pp. 240242.

[16] M. Wintrole, Clinical Hematology, Lea and Febiger, Philadelphia, 1961, pp.143.

[17] J. Porter, Hematol Oncol Clin North Am. 2005, 19, 7.

[18] N. C. Andrews, N Eng J Med. 1999, 341, 1986. 
[19] Z. I. Cabantchik, W. Breuer, G. Zanninelli, P. Cianciulli, Best Pract Res Clin Haematol. 2005, 18, 277.

[20] E. D. Weinberg, Eur J Cancer Prev.1996, 5, 19-36.

[21] M. B. Gholivand, F. Raheedayat, Electroanalysis 2004, 16, 1330.

[22] M. B. Gholivand, F. Sharif pour, Talanta 2003, 60, 707.

[23] S. K. Srivastava, V. K. Gupta, S. Jain, Electroanalysis 1996, 8, 938.

[24] S. K. Srivastava, V. K. Gupta, S. Jain, Anal. Chem. 1996, 68, 1272.

[25] V. K. Gupta, S. Jain, U. Khurana, Electroanalysis 1997, 9, 478.

[26] V. K. Gupta, A. K. Jain, L. P. Singh, U. Khurana, Anal. Chem. Acta. 1997, 355, 33.

[27] A. K. Jain, V. K.Gupta, U. Khurana, L. P. Singh, Electroanalysis 1997, 9, 857.

[28] A. K. Jain, V. K. Gupta, L. P. Singh, U. Khurana, Analyst. 1997, 122, 583.

[29] V. K. Gupta, R. N. Goyal and R. A. Sharma, Electrochem. Acta. 2009, 54, 4216.

[30] V. K. Gupta, R. N. Goyal, A. K. Jain, R. A. Sharma, Talanta 2009, 78, 484.

[31] R. N. Goyal, V. K. Gupta, N. Bachheti, R. A. Sharma, Electroanalysis 2008, 20757.

[32] V. K. Gupta, A. K. Singh, B. Gupta, Combinatorial Chemistry \& High Throughput Screening 2007, 10, 560 .

[33] V. K. Gupta, A. K. Singh, B. Gupta, Combinatorial Chemistry \& High Throughput Screening 2007, 10, 583.

[34] R. N. Goyal, V. K. Gupta, N. Bachheti, Anal. Chem. Acta. 2007, 597, 82.

[35] R. N. Goyal, V. K. Gupta, M. Oyama, N. Bachheti, Talanta 2007, 72, 976.

[36] V. K. Gupta, A. K. Singh, B. Gupta, Anal. Bioanal. Chem. 2007, 389, 2019.

[37] M. Pooyamanesh, H. A. Zamani, G. Rajabzadeh, M. R. Ganjali, P. Norouzi, Anal. Lett. 2007, 40, 1596.

[38] M. H. Mashhadizadeh, I. Sheikh-Shoaei, N. Monadi, Talanta 2004, 64, 1048.

[39] V. K. Gupta, A. K. Jain, S. Agarwal, G. Maheshwari, Talanta 2007, 71, 1964.

[40] A. Sil, V. S. Ijeri, A. K. Srivastava, Sens. Acta. B 2005, 106, 648.

[41] W. H. Mahmoud, Anal. Chem. Acta. 2001, 436, 199.

[42] H. A. Zamani, M. R. Abedi, M. R. Ganjali, J. Chil. Chem. Soc. 2009, 54, 186.

[43] G. Ekmekci, D. Uzun, G. Somer, S. Kalayc1, J. Membr. Sci. 2007, 288, 36.

[44] J. Elias, R. Tena-Zaera, G.-Y. Wang, C. Le'vy-Cle'ment, Chem. Mater 2008, 20, 6633.

[45] H. Zhang, D. Yang, S. Li, X. Ma, Y. Ji, J. Xu, D. Qu, Mater. Lett. 2005, 591696.

[46] M. M. Zareh, I. F. A. Ismail, M. H. A. El-Aziz, Electroanalysis, 2010, 22, 1369.

[47] IUPAC Analytical Chemistry Division, Commission on Analytical Nomenclature, Pure Appl. Chem. 2000, 72, 1851-1856. 


\section{Figure Captions}

Figure 1(a-c). A typical SEM image of $\mathrm{ZnO}$ nanorods grown on gold coated glass substrate using the aqueous chemical growth method. The figure exhibit: (a) the $\mathrm{ZnO}$ nanorods without membrane, (b) the $\mathrm{ZnO}$ nanorods immobilized with ionophore before the use, and in (c) the functionalized $\mathrm{ZnO}$ nanorods after use for sensing.

Figure 2(a-b). (a) The calibration curve for iron sensor, and (b) time response of the iron sensor base on $\mathrm{ZnO}$ nanorods in $10^{-4} \mathrm{M}$ ferric chloride hexahydrate solution.

Figure 3(a-b). (a) Sensor to sensor reproducibility of $(n=4)$, for electrodes in $10^{-4} \mathrm{M}$ ferric chloride hexahydrate solution, and in (b) the response of three different experiments using the same sensor together a $\mathrm{Ag} / \mathrm{AgCl}$ reference electrode.

Figure 4(a-b). (a)The output voltage versus with temperature, and (b) response of electrode against $\mathrm{Fe}^{3+}$ and other interference cations.

Figure 5. The Potentiometric titration curve of $10^{-4} \mathrm{M} \mathrm{Fe}^{3+}(20 \mathrm{ml})$ solution versus with EDTA $\left(10^{-4} \mathrm{M}\right)$. 
Figure 1.

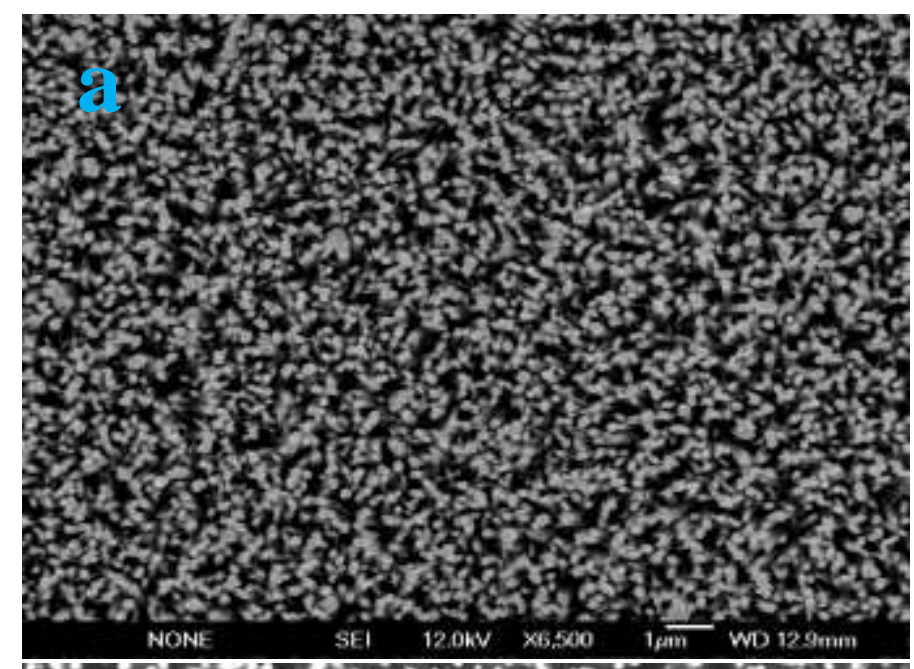

(7) 0 .

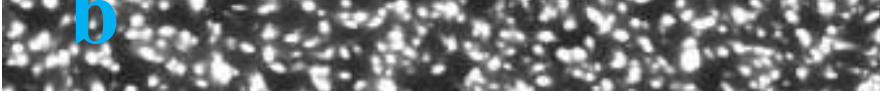

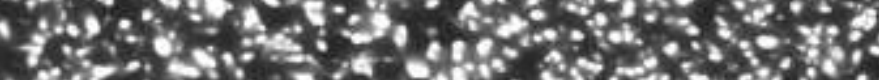
Vot $\because 2.0$ :

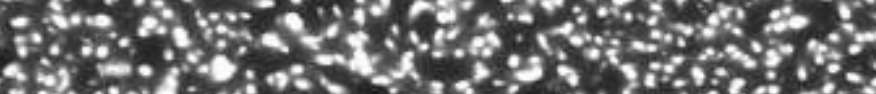

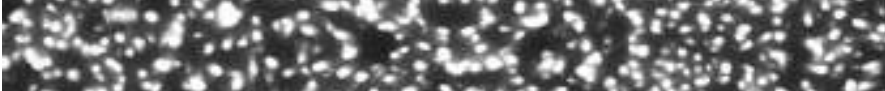

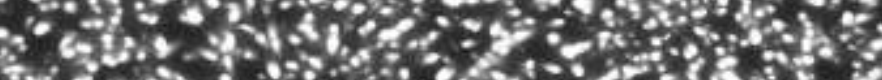

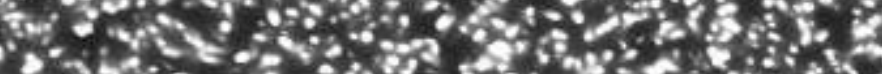

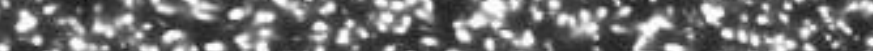

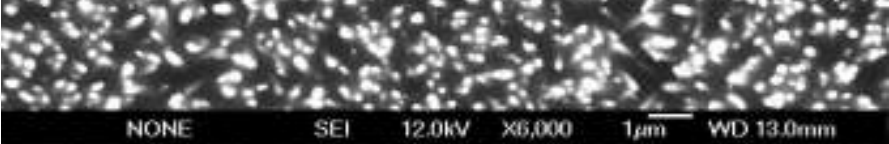

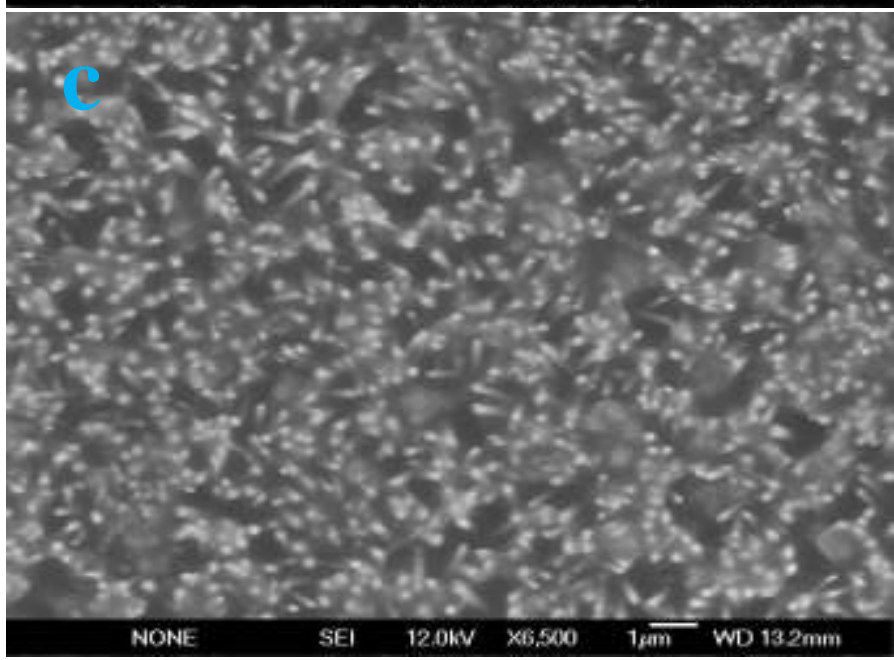


Figure 2.

a)

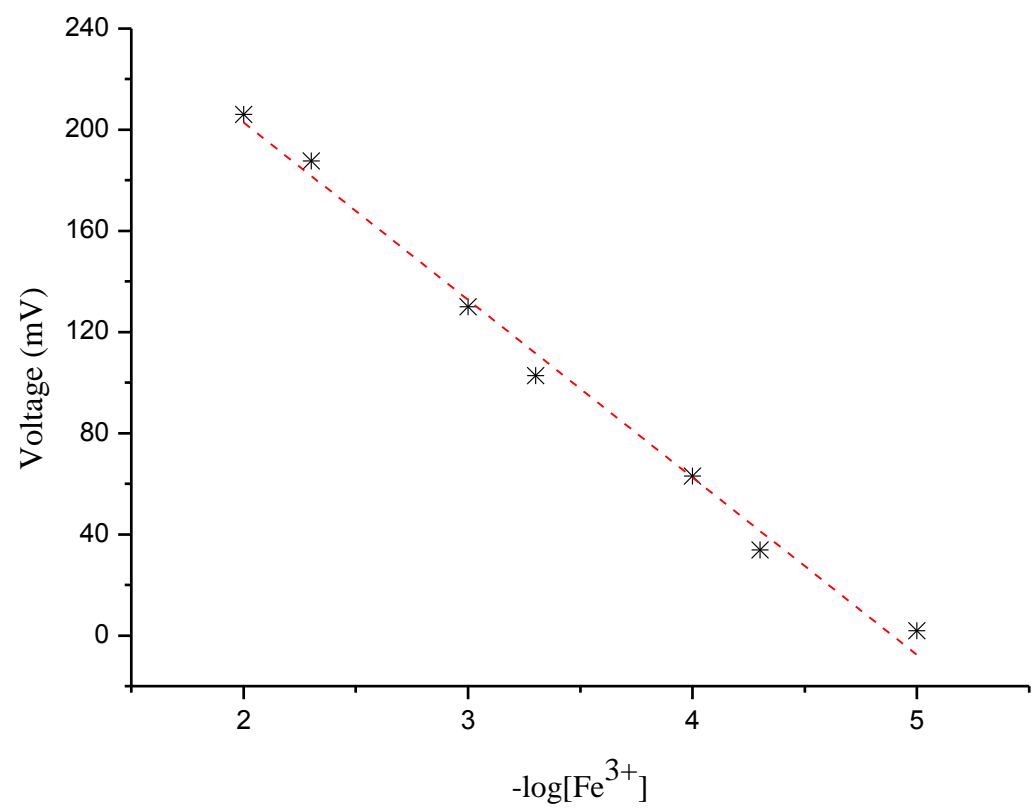

b)

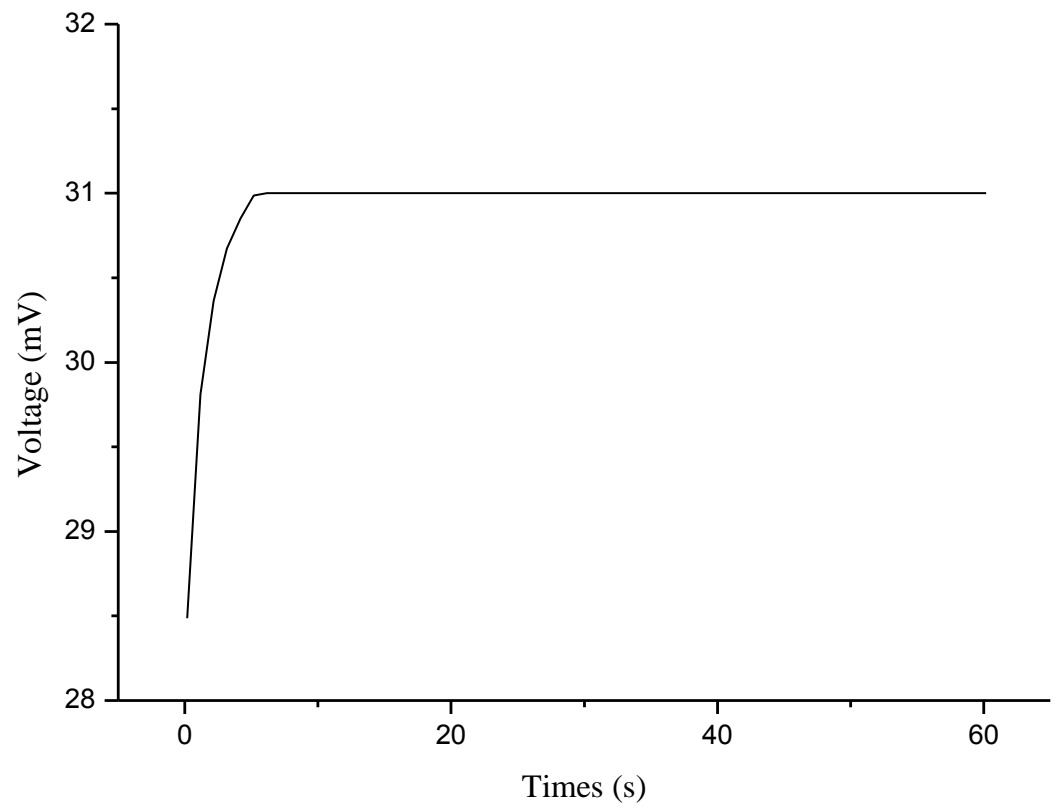


Figure 3.

a)

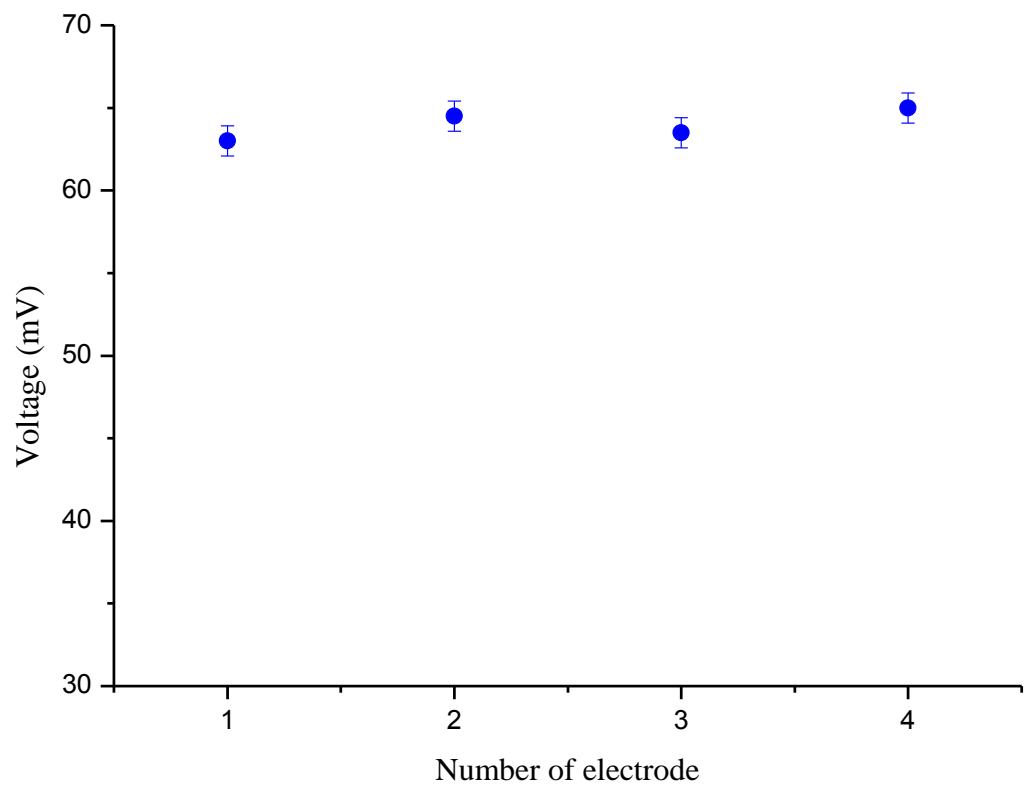

b)

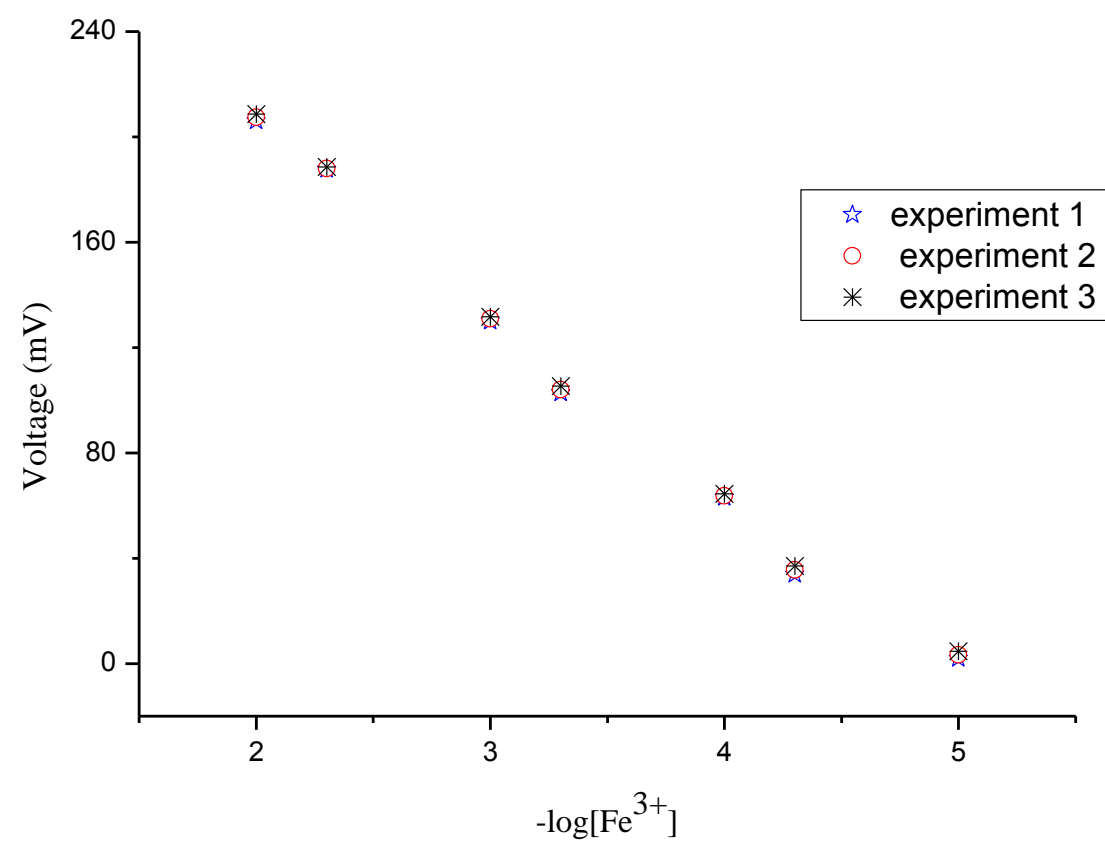




\section{Figure 4.}

a)

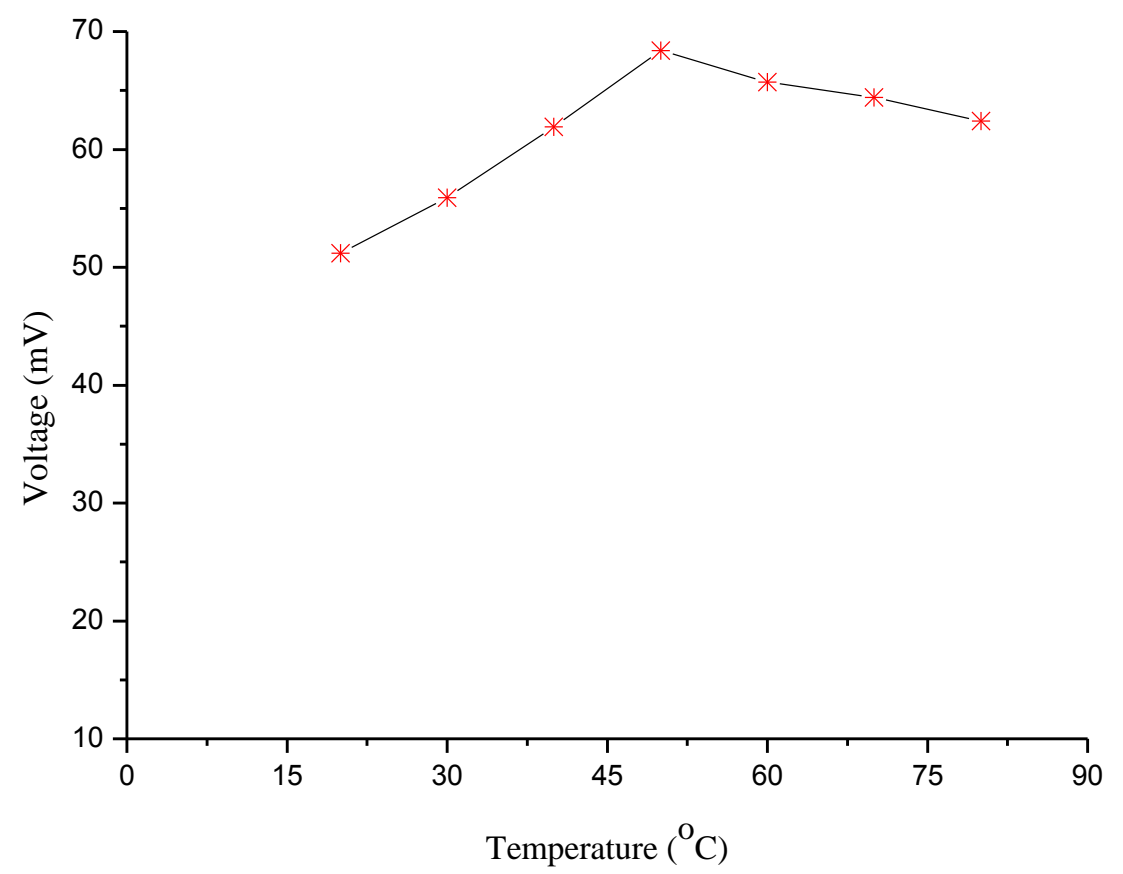

b)

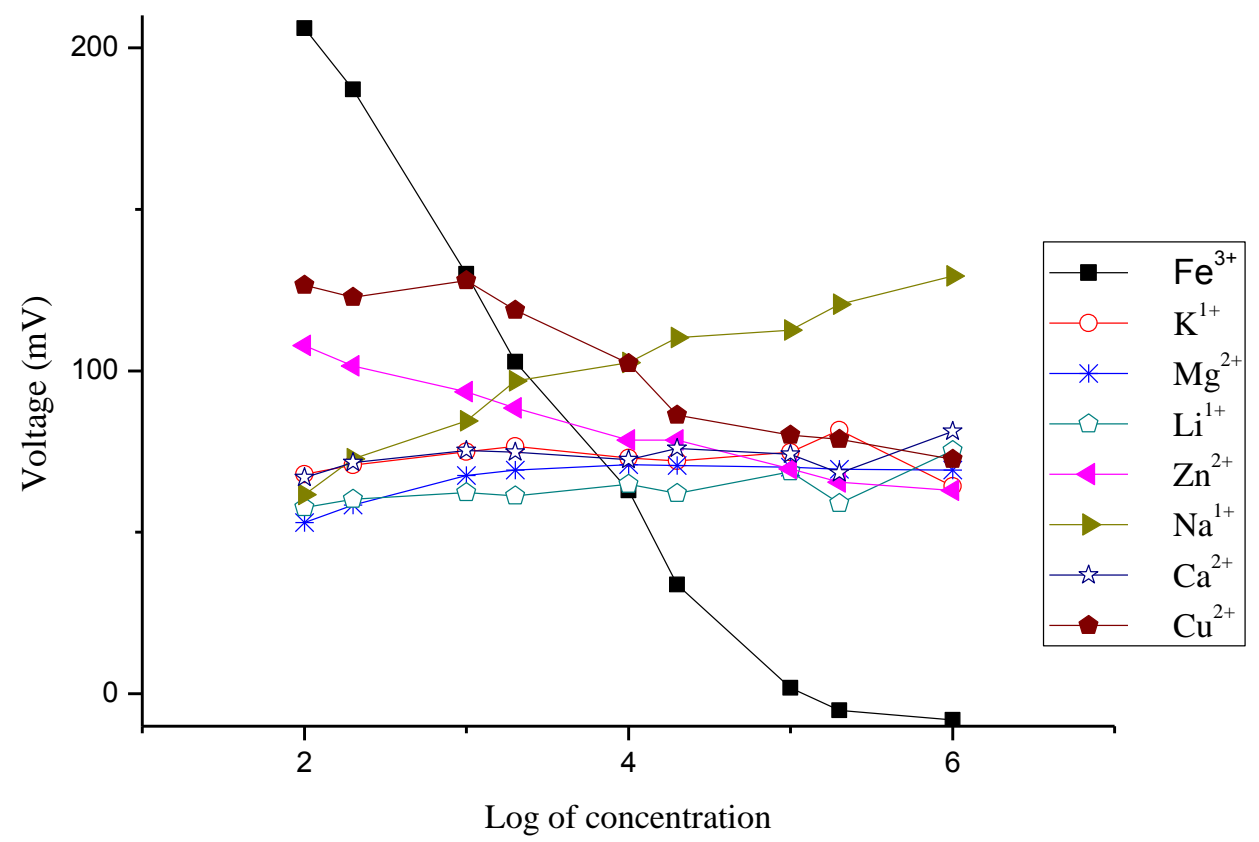


Figure 5.

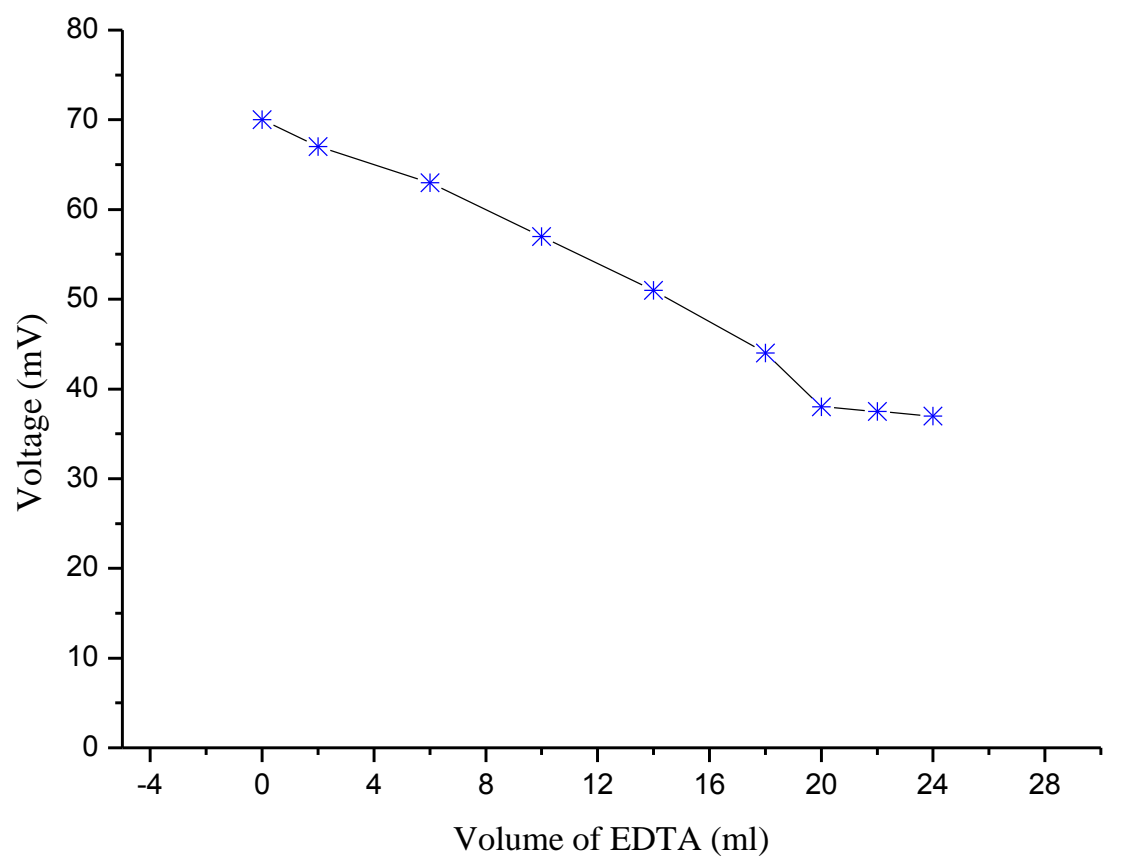

